\title{
Depression and Anxiety Symptoms in a Representative Sample of Undergraduate Students in Spain, Portugal, and Brazil*
}

\author{
Armando Afonso Junior ${ }^{1}$ (D, Anna Carolina de Almeida Portugal ${ }^{2}$ (D, J. Landeira-Fernandez ${ }^{3}$ (D,

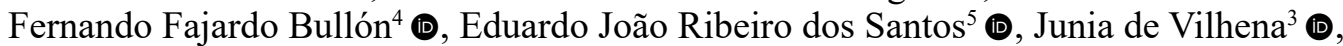 \\ \& Luis Anunciação ${ }^{3, * *}$ (D) \\ ${ }^{1}$ Universidade Presbiteriana Mackenzie, São Paulo, SP, Brazil \\ ${ }^{2}$ Instituto Brasileiro de Neuropsicologia e Ciências Cognitivas, Rio de Janeiro, RJ, Brasil \\ ${ }^{3}$ Pontifícia Universidade Católica do Rio de Janeiro, Rio de Janeiro, RJ, Brazil \\ ${ }^{4}$ Universidad de Extremadura, Caceres, Spain \\ ${ }^{5}$ Universidade de Coimbra, Coimbra, Portugal
}

\begin{abstract}
University students have shown a significant occurrence of depression and anxiety symptoms. This epidemiological work investigated the prevalence of such symptoms in university students in Spain, Portugal, and Brazil, as well as the possible differences according to nationality and gender from a representative sample of three universities (University of Extremadura/Spain, $n=1216$; University of Coimbra/Portugal, $n=426$, and PUC-Rio, $n=315$ ) in 2015 . The results suggest that Brazilian students have a greater manifestation of depression symptoms, especially women, and they also presented greater symptoms of anxiety. No difference was found in the anxiety results between countries. The correlation between depression and anxiety was positive and strong. This study can be of value in social, clinical and political settings.
\end{abstract}

KEYWORDS: Depression, Anxiety, Epidemiology, University students.

\section{Sintomas de Depressão e Ansiedade em uma Amostra Representativa de Universitários Espanhóis, Portugueses e Brasileiros}

\begin{abstract}
RESUMO - Universitários apresentam sintomas importantes de depressão e ansiedade. Este trabalho epidemiológico investigou a prevalência de tais sintomas em acadêmicos da Espanha, Portugal e Brasil, bem como as possíveis diferenças em função da nacionalidade e do gênero a partir de uma amostra representativa de 3 universidades (Universidade de Extremadura/Espanha = 1216; Universidade de Coimbra/Portugal = 426 e PUC-Rio = 315) em 2015. Análises descritivas e inferências indicaram que estudantes brasileiros, em especial as mulheres, apresentam maior manifestação de sintomas de depressão. Elas também apresentaram maior sintomatologia de ansiedade. A correlação entre depressão e ansiedade foi proporcional e forte e não houve diferença na ansiedade entre os países. Esta pesquisa pode ser utilizada em diversas áreas e auxiliar práticas clínicas e políticas públicas.
\end{abstract}

PALAVRAS-CHAVE: Depressão, Ansiedade, Epidemiologia, Universitários

It is known that major depression is an important and recurrent pathology which affects mood, in addition to influencing other factors related to quality of life and mortality (Üstün et al., 2004). Depression symptoms are handicapping in such a way that their persistence prevents returning to individual functionality, while diminishing these symptoms seems to induce functional improvement (Ormel et al., 1993).

\footnotetext{
* Apoio: CNPq; CAPES, MAPFRE.

**E-mail: luisfca@puc-rio.br

n Submetido: 04/10/2017; Revisado: 04/04/2018; Aceito: 25/06/2018.
} 
Following similar directions, anxiety disorders are also a common disorder in psychiatry (American Psychiatric Association, 2013). From the conceptual standpoint, anxiety is a natural, protective and future-oriented condition. However, when anxiety becomes overwhelming or unmanageable, it is counterproductive and handicapping. Thus, anxiety disorders present a myriad of symptoms in physical and cognitive domains, including, but not limited to, muscular tension and excessive sweating, bias in attentional focus to potentially aversive events, as well as abnormal worry about such events (DeSousa et al., 2013). These disorders affect heterogeneous areas such as those related to education, family life, and leisure. Moreover, previous studies suggest that anxiety symptoms are proportionally correlated with depressive symptoms (Andreatini \& Bacellar, 1999; Creswell et al., 2014).

Studies indicate that women represent a risk group in relation to anxiety and depression disorders. The occurrence of such pathologies is approximately twice as high in women than in men (American Psychiatric Association, 2013; Nolen-Hoeksema, 2001; Remes et al., 2016). In addition to gender, other social factors are also involved in the prevalence of anxiety and depression symptoms (Khawaja et al., 2013; Mikolajczyk et al., 2008; Somers, Elliot et al., 2006). Scientific evidence suggests that the socioeconomical level of a country is associated with the presence of higher prevalence of mental disorders (Kessler \& Bromet, 2013; Simou \& Koutsogerogou, 2014). Further findings reveal that less developed countries have a higher prevalence of mental disorders and less treatment availability when compared to more developed countries (Demyttenaere et al., 2004; Wang et al., 2007). However, there is a lack of convergence in the results exploring the influence of nationality on these symptoms (Heinrichs et al., 2006; Ruscio et al., 2017; Schreier et al., 2010).

Major depression is frequently reduced in older adults (Kessler et al., 2010; Kessler \& Bromet, 2013), but results regarding adolescents point to the opposite direction (Lopez et al., 2006). Depression is a main risk factor for suicide in this group, with some studies showing that more than half of victims present depression symptoms at the time of their suicide (Hawton \& van Heeringgen, 2009; Windfuhr et al., 2008). Despite this, it is common that depression and anxiety cases are not properly diagnosed in the young population, and they remain without treatment until adult age (James et al., 2015; Stein \& Fazel, 2015).

A particular group which has shown an increasing manifestation of mental disorders is college / undergraduate students (Ceyhan \& Ceyhan, 2009; Mikolajczyk et al., 2008). Among the factors which seem to influence the prevalence of anxiety and depression in this group is the elevated number of classes, financial stressors and insecurity in relation to entering the job market (Porcu et al., 2001).

However, there are still few studies which have investigated the prevalence of anxiety and depression symptoms in college students, especially those which compare adolescents of different nationalities in relation to symptom presentation.

Therefore, this study examines the prevalence of anxiety and depression symptoms in a representative sample of undergraduate students in Spain, Portugal, and Brazil, and explores the difference in the results gathered by the psychometric inventories with regard to gender and nationality.

\section{METHODS}

This is an epidemiological cross-sectional study to check mental health indicators/status of undergraduate students from three universities (University of Extremadura in Spain; University of Coimbra in Portugal, and Pontifical Catholic University in Brazil) during 2015. Stratified probability sampling was performed, and therefore the evaluated participants were representative of the three institutions.

\section{Participants}

A sample composed of 1,957 undergraduate students were recruited for this study. With regard to proportions, $62.1 \%$ were from the University of Extremadura (Spain), $21.8 \%$ from the University of Coimbra (Portugal), and $16.1 \%$ from the Pontifical Catholic University of Rio de Janeiro (PUC-Rio, Brazil). The mean age of the Spanish students was $21.49(\mathrm{SD}=3.02)$, while it was $20.43(\mathrm{SD}=$ 1.66) for the Portuguese students, and $22.83(\mathrm{SD}=7.18)$ for the Brazilian students.
The sample composition was representative of the three universities. It was composed by stratifying centers or departments, considering an error margin of $4 \%$, heterogeneous population at $50 \%$ and confidence level of $95 \%$. The following formula was implemented to calculate the sample size (Luiz \& Magnanini, 2000):

$$
n=\frac{Z_{\alpha / 2}^{2} * N^{*} p *(1-p)}{E^{2} *(N-1)+Z_{\alpha / 2}^{2} * p^{*}(1-p)}
$$

Where:

$\mathrm{n}=$ sample size

$\mathrm{N}=$ population size

$\mathrm{p}=$ expected prevalence or proportion

$\mathrm{Z}=\mathrm{Z}$ statistic for a level of confidence (1.96 was set in this study)

$\mathrm{E}=$ Precision 


\section{Procedure}

Contacts were made via e-mail and in person with all professors from the three universities in order to reach the necessary sample number in each of the Departments/ Centers so that the sample was correctly stratified. Next, both the faculties of each center as well as the participants to be sampled were randomly drawn and subsequently accessed. The scales were applied in person and carried out by a team of students and previously trained professionals during a specific time frame available for the other professors. All data collection took place outside the period of exams or evaluations to reduce these effects.

All participants were duly informed about the research objective and spent an average of 20 minutes to answer all the instruments. Participants who wished to remain anonymous were instructed to do so. Doubts and information were answered by the research team, which was also responsible for transposing the data to the digital platform.

\section{Measures}

This research implemented the Beck Depression Inventory (BDI-II) and the Beck Anxiety Inventory (BAI).

The Beck Depression Inventory (BDI) is a best self-reported measure of depression and is widely used in research and clinical practice (Gomes-Oliveira et al., 2012; Wang \& Gorenstein, 2013). It is currently in its second edition (BDI-II), which was developed to overcome questions about its content validity evidence based on the DSM-IV diagnostic criteria. The BDI-II is composed of 21 polytomous items which assess the severity of depressive symptoms on a Likert-type scale from 0 to 3 points. This instrument presents validity evidence studies in Spain (Wang \& Gorenstein, 2013), Portugal (Campos \& Gonçalves, 2011), and Brazil (Cunha, 2001). The internal consistency in this study was accessed by Cronbach's alpha coefficient with a result of 0.89 (95\% CI, 0.89-0.9).

The Beck Anxiety Inventory (BAI) is also a self-reported instrument that is widely used in research and clinical practice (Osório et al., 2011). It consists of 21 polytomous items which assess the severity of anxiety symptoms on a 0 to 3-point Likert scale. The instrument presents studies that provide validity evidence in Spain (Magán et al., 2008), Portugal (Quintão et al., 2013) and Brazil (Cunha, 2001). The internal consistency in this study was accessed by Cronbach's alpha coefficient, with a result of $0.9(95 \% \mathrm{CI}, 0.90-0.91)$

\section{Statistical analysis}

The database was initially checked for errors (e.g., typos and computational inconsistency). Missing values were visually identified to explore and detect any patterns in its randomness. No data imputations were employed as missing data were less than 5\% for each variable of interest. The items of both instruments were summed except for participants in which all responses of BDI-II or BAI were absent (as suggested in the test guidelines), which resulted in a value for each participant (Beck et al., 1988; Beck, Steer \& Brown, 1996),

The following cut-off points were used for BDI-II: values less than or equal to 13, minimal depression; values greater than 13 and less than 20, light; values greater than or equal to 20 and less than 29, moderate; and values greater than or equal to 29 , severe. For BAI, values less than or equal to 10 were considered as minimal anxiety; values above 10 and less than 20, mild anxiety; values greater than or equal to 20 and less than 31, moderate anxiety; and values equal to or above 31, severe anxiety (Cunha, 2001).

Categorical variables were presented by counts and proportions. Continuous variables were summarized by mean, standard deviation, median, and median absolute deviation (MAD). For inferential procedures, regression models were adjusted and their diagnoses were carried out, which suggested the violation of normality assumptions of residuals and homoscedasticity. Thus, the Kruskal-Wallis test was used to investigate the differences between the three countries, and the Mann-Whitney test was used to verify differences between the results according to gender.

Post-hoc comparisons were performed using the Tukey method (Kramer Nemenyi test) and the size of the effect was calculated by $\eta 2$ based on the H statistic. Spearman correlation was used between the results of the inventories.

The value of 0.05 was set for Type I Error and all analyzes were performed in R 3.6 (R core team, 2017), with the tidyverse (Wickham, 2016), olsrr (Hebbali, 2018), and rstatix packages (Kassambara, 2020). All codes are available at https://osf.io/xpvbg/

\section{Ethical consent}

This study was approved by the Research Ethics Committee (CEP) of the University of Extremadura under number 2014-92, Coimbra, under number 17-2014 and PUC-Rio under number 2015-5. 


\section{RESULTS}

As described, a sample composed of 1,957 participants were assessed in the three countries. The majority were from Spain (62.1\%), followed by Portugal (21.8\%) and Brazil (16.1\%). The mean age of the participants varied

Table 1

Demographic variables and the main results.

\begin{tabular}{lccccccccc}
\hline \multirow{2}{*}{ Country } & \multicolumn{2}{c}{ Participants } & \multicolumn{3}{c}{ Gender (\%) } & \multicolumn{3}{c}{ Age } \\
\cline { 2 - 10 } & $\mathbf{N}$ & $\mathbf{\%}$ & Male & Female & P & Total & Male & Female & P \\
\hline Spain & 1.216 & $62.1 \%$ & $384(32 \%)$ & $825(68 \%)$ & $<.01$ & $21.49(3.02)$ & $21.43(3.48)$ & $21.52(2.77)$ & .67 \\
Portugal & 426 & $21.8 \%$ & $203(48 \%)$ & $223(52 \%)$ & .33 & $20.43(1.66)$ & $20.51(1.64)$ & $20.37(1.68)$ & .39 \\
Brazil & 315 & $16.1 \%$ & $149(47 \%)$ & $166(53 \%)$ & .34 & $22.83(7.18)$ & $22.13(4.31)$ & $23.41(8.87)$ & .11 \\
Total & 1.957 & $100 \%$ & $736(38 \%)$ & $1214(62 \%)$ & & $21.46(3.83)$ & $21.30(3.31)$ & $21.56(4.11)$ \\
\hline
\end{tabular}

Note: There were 7 missing cases of sex

Table 2

Beck Depression Inventory II and Beck Anxiety Inventory results.

\begin{tabular}{|c|c|c|c|c|c|c|c|c|c|c|c|c|}
\hline & \multicolumn{6}{|c|}{ BDI-II (Beck Depression Inventory - II) } & \multicolumn{6}{|c|}{ BAI (Beck Anxiety Inventory) } \\
\hline & \multirow{2}{*}{$\begin{array}{c}\text { Mean } \pm \text { SD } \\
(\text { Median } \pm \\
\text { MAD) }\end{array}$} & \multicolumn{4}{|c|}{ Classification \% } & \multirow[b]{2}{*}{$p$} & \multirow{2}{*}{$\begin{array}{c}\text { Mean } \pm \text { SD } \\
(\text { Median } \pm \\
\text { MAD) }\end{array}$} & \multicolumn{4}{|c|}{ Classification \% } & \multirow[b]{2}{*}{$p$} \\
\hline & & Minimal & Mild & Moderate & Severe & & & Minimal & Mild & Moderate & Severe & \\
\hline Spain & $\begin{array}{c}8.86 \pm 7.54 \\
(7 \pm 5.93)\end{array}$ & 80.4 & 11.4 & 5.69 & 2.56 & $<.001$ & $\begin{array}{c}8.55 \pm 8.06 \\
(6 \pm 5.93)\end{array}$ & 71.2 & 19.0 & 7.17 & 2.64 & $<.001$ \\
\hline Portugal & $\begin{array}{c}9.05 \pm 7.73 \\
(7 \pm 5.93)\end{array}$ & 79.0 & 11.8 & 6.38 & 2.84 & $<.001$ & $\begin{array}{c}7.92 \pm 8.04 \\
(5 \pm 5.93)\end{array}$ & 72.6 & 18.4 & 5.90 & 3.07 & $<.001$ \\
\hline Brazil & $\begin{array}{c}10.89 \pm 8.29 \\
(9.5 \pm 8.15)\end{array}$ & 68.8 & 16.2 & 10.8 & 4.14 & $<.001$ & $\begin{array}{c}9.01 \pm 8.40 \\
(6 \pm 5.93)\end{array}$ & 67.3 & 21.6 & 8.25 & 2.86 & $<.001$ \\
\hline$p$-value & $<.001$ & & & & & & .06 & & & & & \\
\hline $\begin{array}{l}\text { Effect } \\
\text { Size }\end{array}$ & .01 & & & & & & $<.01$ & & & & & \\
\hline Male & $\begin{array}{c}8.68 \pm 7.74 \\
(7 \pm 5.93)\end{array}$ & 81.0 & 10.7 & 5.05 & 3.28 & $<.001$ & $\begin{array}{c}6.81 \pm 7.14 \\
(5 \pm 4.45)\end{array}$ & 79.8 & 13.8 & 4.38 & 2.05 & $<.001$ \\
\hline Female & $\begin{array}{c}9.59 \pm 7.73 \\
(8 \pm 7.41)\end{array}$ & 76.4 & 13.2 & 7.69 & 2.64 & $<.001$ & $\begin{array}{c}9.47 \pm 8.45 \\
(7 \pm 5.93)\end{array}$ & 65.7 & 22.5 & 8.73 & 3.13 & $<.001$ \\
\hline$p$-value & .001 & & & & & & $<.001$ & & & & & \\
\hline $\begin{array}{l}\text { Effect } \\
\text { Size }\end{array}$ & .073 & & & & & & .18 & & & & & \\
\hline
\end{tabular}

significantly in the three countries $(\mathrm{F}(2,1926)=35.19, \mathrm{p}<$ $.001)$, but the overall mean was 21.5 years $(\mathrm{SD}=3.8)$. The proportions of males and females were similar in Portugal and Brazil, but significantly different in Spain $(X 2(1)=161$, $\mathrm{p}<.001)$. Table 1 describes these main results.

Regression models were fitted and the distribution of residuals was analyzed via the Shapiro-Wilk test, which indicated that assumption of normality was violated: BDI -II $(\mathrm{W}=0.88, \mathrm{p}<.01)$ and BAI $(\mathrm{W}=0.84, \mathrm{p}<.01)$. The analyzes of the depression and anxiety scores were carried out independently to explore differences by country and gender. The results are presented in Table 2.

The depression and anxiety levels were compared between countries using the Kruskal-Wallis test and the differences between groups were verified using the Kramer Nemenyi test as post hoc. The BDI results revealed that Brazil has the highest result $(\mathrm{M}=10.89, \mathrm{SD}=8.29$, Median $=9.5 ; \mathrm{MAD}=8.15)$, as well as a significantly higher value when compared to both Spain $(\mathrm{p}<.01)$, and Portugal $(\mathrm{p}<$ $.01)$. Regarding anxiety, no difference was found between countries $(\mathrm{KW}(2)=5.8, \mathrm{p}=.06)$.

The results between men and women were compared using the Mann-Whitney test, which concluded that women had a higher result of both depression $(\mathrm{W}=404216, \mathrm{p}=.001)$ and anxiety $(\mathrm{W}=348512, \mathrm{p}<.001)$. Regarding depression, women had a mean of $9.59(\mathrm{SD}=7.73)$ and a median of 8 $(\mathrm{MAD}=7.41)$, while men had a mean result of $8.68(\mathrm{SD}=$ $7.74)$ and a median of $7(\mathrm{MAD}=5,93)$. Regarding anxiety, 
women had a mean result of $9.47(\mathrm{SD}=8.45)$ and a median of $7(\mathrm{MAD}=5.93)$, while men had a mean result of 6.81 $(\mathrm{SD}=7.14)$ and a median of $5(\mathrm{MAD}=4,45)$.

Similar to many psychological tests, both BDI and BAI use the scores obtained by respondents to place them into broad and distinct categories. These categories are useful to help make a diagnosis or clinical monitoring.
Most participants had results in the "Minimal range", suggesting they were not experiencing depression or dysfunctional anxiety during this study. The correlation between the results of anxiety and depression included data from the three countries and the result was positive and strong $(R h o=0.58, p<.001)$, indicating that both variables move in tandem, which means in the same direction.

\section{DISCUSSION}

To the best of our knowledge, this is the first epidemiological study which has investigated the prevalence of depression and anxiety symptoms using a representative sample of undergraduate students from Spain, Portugal, and Brazil. Our main results make it possible to conclude that students from Brazil showed a higher manifestation of depressive symptoms when compared to students from the other two countries investigated. However, the results with regard to anxiety symptoms were not significant. Furthermore, our outcomes show that depressive and anxiety symptomatology is more prevalent in women than in men, regardless of their nationality. Moreover, it is also possible to state that anxiety symptoms are proportionally related to depressive symptoms, even if there is no indication of causality.

Regarding the results on nationality, the higher Brazilian score on the depression inventory opens multiple perspectives of interpretation and understanding and we are aware that this result can be confounded by other variables. One avenue is the different socio-economical level between Brazil and Spain and Portugal. Some researchers suggest that income inequality is a main factor which causes an increase in depressive symptoms (Kessler \& Bromet, 2013; Koplewicz et al., 2009; Wilkinson \& Pickett, 2006).

In this study we also concluded an absence of statistical differences in the anxiety results between students from the three surveyed countries. Previous studies have revealed a remarkable lack of consensus on the possible relationship or impact of nationality in this symptomology. Some authors suggest that collectivist countries present higher social anxiety (Heinrichs et al., 2006; Schreier et al., 2010), while others suggest that a higher financial level would be associated with anxiety symptoms (Ruscio et al., 2017).

The higher scores of women than men on anxiety and depression psychometric instruments are consistent with past studies. There are some possible explanations for this outcome. Regarding the possibilities, the role of hormonal mechanisms (Maeng \& Milad, 2015), a greater sensitivity to anxiety (Armstrong \& Khawaja, 2002), as well as the higher reactivity to stress among women when compared to men (Nolen-Hoeksema, 2001) can be hypothesized. Furthermore, our findings herein are convergent with the epidemiology descriptions of the fifth edition of the Diagnostic and Statistical Manual of Mental Disorders (American Psychiatric Association, 2013).

A direct and strong correlation between the results obtained by the anxiety and depression measures in the three countries add more evidence of the association between depressive and anxiety symptoms, especially among young adults (e.g., Eisenberg et al., 2007; Stein et al., 2001). However, we stress that new results are necessary, mainly because this association result probably varies according to anxiety subtypes or other confounders (Cummings et al., 2015).

This study has some limitation which should be considered when generalizing the results. The sample was only composed of undergraduate students and despite their representativeness of the three surveyed institutions (PUCRio, University of Extremadura, and University of Coimbra), it is not representative of all other universities, especially for those with diverse contextual characteristics. However, on-parametric procedures were used to help avoid inferential pitfalls to reduce the probability of type 1 error.

Despite these limitations, due to the scarcity of research with probabilistic design methods on the influence of cultural background on anxiety and depression symptoms in young undergraduate students, the results obtained in this study are of value to contribute to formulating social, clinical, and public policies for these groups in the three studied groups (Ceyhan \& Ceyhan, 2009; Cooper et al., 2008; James et al., 2015; Kessler \& Bromet, 2013; Simou \& Koutsogeorgou, 2014; Stein \& Fazel, 2015).

\section{CONCLUSIONS}

This study investigated the prevalence of depressive and anxiety symptoms in undergraduate students from three different and diverse countries. Depressive symptoms were higher in Brazilian students, and especially in women. There was no difference in anxiety symptoms between all countries surveyed, however, women presented a higher anxiety symptom regardless of the participant's nationality, as pointed out in the results from the psychometric inventories. There was a proportional and strong correlation between anxiety and depressive symptoms. 
The reach of these results can be utilized beyond this study in multiple areas, including to help in clinical and educational decisions, as well as public policies. Other studies are in progress.

\section{REFERENCES}

American Psychiatric Association. (2013). DSM-5. Diagnostic and statistical manual of mental disorders (5th ed.). Arlington, VA: American Psychiatric Publishin

Andreatini, R., \& Bacellar, L. F. S. (1999). The relationship between anxiety and depression in animal models: a study using the forced swimming test and elevated plus-maze. Brazilian Journal of Medical and Biological Research, 32(9), 11211126. https://doi.org/10.1590/S0100-879X1999000900011

Armstrong, K. A., \& Khawaja, N. G. (2002). Gender Differences in Anxiety: an Investigation of the Symptoms, Cognitions, and Sensitivity Towards Anxiety in a Nonclinical Population. Behavioural and Cognitive Psychotherapy, 30(2), 227-231. https://doi.org/10.1017/S135246580200211

Beck, A. T., Epstein, N., Brown, G., \& Steer, R. A. (1988). An inventory for measuring clinical anxiety: Psychometric properties. Journal of Consulting and Clinical Psychology, 56(6), 893-897. https://doi.org/10.1037/0022-006X.56.6.893

Beck, A., Steer, R., \& Brown, G. (1996). Beck Depression Inventory-II. San Antonio. https://doi.org/10.1037/t00742-000

Campos, R. C., \& Gonçalves, B. (2011). The Portuguese Version of the Beck Depression Inventory-II (BDI-II). European Journal of Psychological Assessment, 27(4), 258-264. https://doi. org/10.1027/1015-5759/a000072

Ceyhan, A. A., \& Ceyhan, E. (2009). Investigation of University Students 'Depression*, (36), 75-76.

Cooper, C., Bebbington, P. ?E., Meltzer, H., Bhugra, D., Brugha, T., Jenkins, R., ... King, M. (2008). Depression and common mental disorders in lone parents: results of the 2000 National Psychiatric Morbidity Survey. Psychological Medicine, 38(03). https://doi.org/10.1017/S0033291707001493

Creswell, C., Waite, P., \& Cooper, P. J. (2014). Assessment and management of anxiety disorders in children and adolescents. Archives of Disease in Childhood, 99(7), 674-678. https://doi. org/10.1136/archdischild-2013-303768

Cummings, C. M., Caporino, N. E., \& Kendall, P. C. (2015). Adolescents : 20 Years After, 140(3), 816-845. https://doi. org/10.1037/a0034733.Comorbidity

Cunha, J. A. (2001). Manual da versão em português das Escalas de Beck. Casa do Psicólogo.

Demyttenaere, K., Bruffaerts, R., Posada-Villa, J., Gasquet, I., Kovess, V., Lepine, J.P., Angermeyer, M.C., Bernert, S., de Girolamo, G., Morosini, P., Polidori, G., Kikkawa, T., Kawakami, N., Ono, Y., Takeshima, T., Uda, H., Karam, E.G., Fayyad, J.A., Karam, A.N., Mneimneh, Z.N., Medina-Mora, M.E., Borges, G., Lara, C., de Graaf, R., Ormel, J., Gureje, O., Shen, Y., Huang, Y., Zhang, M., Alonso, J., Haro, J. M., Vilagut, G., Bromet, E. J., Gluzman, S., Webb, C., Kessler, R. C., Merikangas, K. R., Anthony, J. C., Von Korff, M. R., Wang, P. S., Brugha, T. S., Aguilar-Gaxiola, S., Lee, S., Heeringa, S., Pennell, B. E., Zaslavsky, A. M., Ustun, T. B., Chatterji, S., \& WHO World Mental Health Survey Consortium. (2004). Prevalence, severity and unmet need for treatment of mental disorders in the World Health Organization World Mental Health Surveys. JAMA, 291(21) 2581-2590. https://doi. org/10.1001/jama.291.21.2581

DeSousa, D. A., Moreno, A. L, Gauer, G., Manfro, G. G., \& Koller, S. H. (2013). Revisão sistemática de instrumentos para avaliação de ansiedade na população brasileira [Systematic review of instruments to evaluate anxiety in Brazilian population]. Avaliação Psicológica, 12(3), 397-410.
Eisenberg, D., Gollust, S. E., Golberstein, E., \& Hefner, J. L. (2007). Prevalence and correlates of depression, anxiety, and suicidality among university students. American Journal of Orthopsychiatry, 77(4), 534-542. https://doi. org/10.1037/0002-9432.77.4.534

Gomes-Oliveira, M. H., Gorenstein, C., Neto, F. L., Andrade, L. H., \& Wang, Y. P. (2012). Validation of the Brazilian Portuguese Version of the Beck Depression Inventory-II in a community sample. Revista Brasileira de Psiquiatria, 34(4), 389-394. https://doi.org/10.1016/j.rbp.2012.03.005

Hawton, K., \& van Heeringen, K. (2009). Suicide. Lancet, 373, 1372-1381. https://doi.org/10.1016/S0140-6736(09)60372-X

Hebbali, A. (2018). olsrr: Tools for Building OLS Regression Models. R package version 0.5.2. Retrieved from https:// cran.r-project.org/package $=$ olsrr

Heinrichs, N., Rapee, R. M., Alden, L. A., Bögels, S., Hofmann, S. G., Ja Oh, K., \& Sakano, Y. (2006). Cultural differences in perceived social norms and social anxiety. Behaviour Research and Therapy, 44(8), 1187-1197. https://doi.org/10.1016/j. brat.2005.09.006

James, A. C., James, G., Cowdrey, F. A., Soler, A., Choke, A., Ac, J., ... Choke, A. (2015). Cognitive behavioural therapy for anxiety disorders in children and adolescents ( Review ). The Cochrane Database of Systematic Reviews, 2(2), 1-108. https://doi.org/10.1002/14651858.CD004690.pub4.www. cochranelibrary.com

Kassambara, A. (2020). rstatix: Pipe-Friendly Framework for Basic Statistical Tests, https://CRAN.R-project.org/package=rstatix

Kessler, R. C., Birnbaum, H. G., Shahly, V., Bromet, E., Hwang, I., McLaughlin, K. A., Sampson, N., Andrade, L.H., de Girolamo, G., Demyttenaere, K., Haro, J. M., Karam, A. N., Kostyuchenko, S., Kovess, V., Lara, C., Levinson, D., Matschinger, H., Nakane, Y., Browne, M. O., Ormel, J., ... Stein, D. J. (2010). Age differences in the prevalence and comorbidity of DSM-IV major depressive episodes: Results from the WHO world mental health survey initiative. Depression and Anxiety, 27(4), 351-364. https://doi.org/10.1002/da.20634

Kessler, R. C., \& Bromet, E. J. (2013). The Epidemiology of Depression Across Cultures. Annual Review of Public Health, 34(1), 119-138. https://doi.org/10.1146/annurevpublhealth-031912-114409

Khawaja, N. G., Santos, M. L. R., Habibi, M., \& Smith, R. (2013). University students' depression: a cross-cultural investigation. Higher Education Research \& Development, 32(3), 392-406. https://doi.org/10.1080/07294360.2012.697129

Koplewicz, H. S., Gurian, A. \& Williams, K. (2009). The era of affluence and its discontents. Journal of the American Academy of Child and Adolescent Psychiatry, 48(11), 1053-1055. https:// doi.org/10.1097/CHI.0b013e3181b8be5c

Lopez, A., Mathers, C., Ezzati, M., Jamison, D., \& Murray, C. (2006). Global burden of disease and risk factors. Washington: Oxford University Press and the World Bank

Luiz, R. R., \& Magnanini, M. M. (2000). A lógica da determinaçäo do tamanho da amostra em investigaçöes epidemiológicas [The logic of sample size determination in epidemiological research]. Cadernos Saúde Coletiva, 8(2), 9-28.

Maeng, L. Y., \& Milad, M. R. (2015). Sex differences in anxiety disorders: Interactions between fear, stress, and gonadal hormones. Hormones and Behavior, 76, 106-117. https://doi. org/10.1016/j.yhbeh.2015.04.002 
Magán, I., Sanz, J., \& García-Vera, M. P. (2008). Psychometric properties of a Spanish version of the Beck Anxiety Inventory (BAI) in general population. The Spanish Journal of Psychology, 11(2), 626-640. https://doi.org/10.1017/ S1138741600004637

Mikolajczyk, R. T., Maxwell, A. E., Naydenova, V., Meier, S., \& El Ansari, W. (2008). Depressive symptoms and perceived burdens related to being a student: Survey in three European countries. Clinical Practice and Epidemiology in Mental Health, 4(1), 19. https://doi.org/10.1186/1745-0179-4-19

Nolen-hoeksema, S. (2010). Gender Differences in Depression. Psychological Science, 10(5), 173-176. https://doi. org/10.1111/1467-8721.00142

Ormel, J., Oldehinkel, T., Brilman, E., \& van den Brink, W. (1993) Outcome of depression and anxiety in primary care. A threewave study of psychopathology and disability. Archieves of General Psychiatry, 50(10), 759-766.

Osório, F. L., Crippa, J. A., \& Loureiro, S. R. (2011). Further psychometric study of the Beck Anxiety Inventory including factorial analysis and social anxiety disorder screening. International Journal of Psychiatry in Clinical Practice, 15(4), 255-262. https://doi.org/10.3109/13651501.2011.6 05955

Porcu, M., Fritzen, C.V., \& Helber, C. (2001). Sintomas depressivos nos estudantes de medicina da Universidade Estadual de Maringá. Psiquiatria na Prática Médica, 34(1), 2-6

Quintão, S., Delgado, A. R., \& Prieto, G. (2013). Validity study of the Beck Anxiety Inventory (Portuguese version) by the Rasch Rating Scale model. Psicologia: Reflexão e Crítica, 26(2), 305-310. https://doi.org/10.1590/S0102-79722013000200010

R core team. (2017). R: A language and environment for statistical computing. R Foundation for Statistical Computing, Vienna, Austria. https://doi.org/http://www.R-project.org/

Remes, O., Brayne, C., van der Linde, R., \& Lafortune, L. (2016). A systematic review of reviews on the prevalence of anxiety disorders in adult populations. Brain and Behavior, 6(7), 1-33. https://doi.org/10.1002/brb3.497

Ruscio, A. M., Hallion, L. S., Lim, C. C. W., Aguilar-Gaxiola, S., AlHamzawi, A., Alonso, J., Andrade, L.H., Borges, G., Bromet, E. J., Bunting, B., Caldas de Almeida, J. M., Demyttenaere, K., Florescu, S., de Girolamo, G., Gureje, O., Haro, J. M., He, Y., Hinkov, H., Hu, C., . . . Scott, K. M. (2017). Cross-sectional Comparison of the Epidemiology of DSM-5 Generalized Anxiety Disorder Across the Globe. JAMA Psychiatry, 74(5), 465. https://doi.org/10.1001/jamapsychiatry.2017.0056

Schreier, S.-S., Heinrichs, N., Alden, L., Rapee, R. M., Hofmann, S. G., Chen, J., ... Bögels, S. (2010). Social anxiety and social norms in individualistic and collectivistic countries. Depression and Anxiety, 27(12), 1128-1134. https://doi.org/10.1002/ da. 20746

Simou, E., \& Koutsogeorgou, E. (2014). Effects of the economic crisis on health and healthcare in Greece in the literature from 2009 to 2013: A systematic review. Health Policy, 115(2-3), 111-119. https://doi.org/10.1016/j.healthpol.2014.02.002

Somers, J. M., Elliot, M. G., Waraich, P., \& Hsu, L. (2006). Prevalence and Incidence Studies of Anxiety Disorders: A systematic review of the literature. Canada Journal of Psychiatry, 51(2), 100-113. https://doi.org/10.1177/070674370605100206

Stein, K., \& Fazel, M. (2015). Depression in young people often goes undetected. The Practitioner, 259(1782).

Stein, M. B., Fuetsch, M., \& Müller, N. (2001). Social Anxiety Disorder and the Risk of Depression: A Prospective Community Study of Adolescents and Young Adults. Archieves of General Psychiatry, 58(3), 251-256. https://doi.org/10.1001/ archpsyc.58.3.251

Ustün, T. B., Ayuso-Mateos, J. L., Chatterji, S., Mathers, C., \& Murray, C. J. L. (2004). Global burden of depressive disorders in the year 2000. British Journal of Psychiatry, 184, 386-92. https://doi.org/10.1192/bjp.184.5.386

Wang, P. S., Aguilar-Gaxiola, S., Alonso, J., Angermeyer, M. C., Borges, G., Bromet, E. J., Bruffaerts, R., Girlolamo, G., Graaf, R., Gureje, O., Haro, J. M., Karam, E. G., Kessler, R. C., Kovess, V., Lane, M. C., Lee, S., Levinson, D., Ono, Y., Petukhova, M., Posada-Villa, J., Seedat, S., \& Wells, J. E. (2007). Use of mental health services for anxiety, mood, and substance disorders in 17 countries in the WHO world mental health surveys. Lancet, 370(9590), 841-850. https:// doi.org/10.1016/S0140-6736(07)61414-7

Wang, Y.-P., \& Gorenstein, C. (2013). Psychometric properties of the Beck Depression Inventory-II: a comprehensive review. Revista Brasileira de Psiquiatria, 35(4), 416-431. https://doi. org/10.1590/1516-4446-2012-1048

Wickham, H. (2016). tidyverse: Easily Install and Load "Tidyverse" Packages. $R$ package version 1.0.0. Retrieved from https:// cran.r-project.org/package $=$ tidyverse

Wilkinson, R. G., \& Pickett, K. E. (2006). Income inequality and population health: a review and explanation of the evidence. Social Science \& Medicine, 62(7), 1768-1784. https://doi. org/10.1016/j.socscimed.2005.08.03

Windfuhr, K., While, D., Hunt, I., Turnbull, P., Lowe, R., Burns, J., Swinson, N., Shaw, J., Appleby, L., Kapur, N., \& National confidential inquiry into suicide and homicide by people with mental illness. (2008). Suicide in juveniles and adolescents in the United Kingdom. Journal of Child Psychology and Psychiatry, 49(11), 1155-1165. https://doi.org/10.1111/j.14697610.2008.01938.x 